\section{Potential energy}

Developments on Britain's energy front are continuing apace. Chris Sherwell reports

GAS, coal, oil and nuclear power have all featured in the past week's energy developments. At the risk of involving the Cabinet and angering the unions, the Energy Secretary, Mr Anthony Wedgwood Berin, is proposing to overrule the Price Commission's rejection of the British Gas Corporation's (BGC) application for a price rise. The rise, effective next month, will boost BGC revenues by $10 \%$ and is part of the attempt to rationalise Britain's energy industries.

The development came after news that additional coal resources amounting to more than 200 million tonnes have been discovered in Warwickshire. The seams compare with the Selby and Vale of Belvoir fields, and are the result of the National Coal Board's exploration programme. A new $£ 50$ million three-year programme is due to start soon, and more discoveries are expected.

But not everything is rosy. Coal prices are also going up next month; NCB projections of output until the 1980s under its Plan for Coal show that exploitation of new mines is beset by problems in obtaining planning approval; and productivity shows a downward trend.

On the oil front the important matter of depletion policy in the North Sea is attracting attention. The issue emerged clearly recently in the Department of Energy's broad review for the NEDC. An annex stated that large-scale licencing in the early 1970 s was designed to build up an exportable surplus in the 1980s; delays in starting work on new fields and "slippage" in the build-up of commercial fields, however, had "somewhat eroded the level of production expected in the early 1980 s and therefore the export surplus".

back to about 1900 are quite good for large earthquakes, the estimate of magnitude for many of these events leaves a lot to be desired; any analysis which then looks at the statistics of

\section{Quake patterns}

There is regular seismic activity in a band running down the east coast of the Adriatic, through the Aegean Sea and off into Northern Turkey, but further north, activity is rare, suggesting that the major active plate boundaries run well south of Romania. There is, however, a little activity along the north coast of the Black Sea, and a small isolated pocket of Romanian quakes lies along the continuation of this line at the southern most limit of the Carpathian mountains. These quakes are at a depth of 50 to $150 \mathrm{~km}$ and lie in a vertical slab (Nature 228, 1176-8 (1970)); the slab is probably the relic of a small segment of ocean that was overridden millions of years ago but is still out of equilibrium with its surroundings. The earthquakes would then result from the release of stress as the slab settled.

Since the recent quake there have been several attempts to discern patterns in the times of occurrence of Romanian earthquakes. Rarely can credence be attached to such statements which have been made on the basis of a rapidly compiled historic compilation. Although the catalogues
Last week a slightly more optimistic prognosis for the export surplus was produced by a policy adviser to the British Petroleum Board, who counselled against a strict depletion policy designed to prolong the period of selfsufficiency. The issue looks like becoming increasingly important as the time for critical nuclcar power decisions draws closer.

Arguably the most important of those decisions concerns the fast breeder reactor. One report this week says there are suggestions for a supervisory board, representing all concerned interests, to manage the project; an executive team of experts would report to it. The Prototype Fast Reactor at Dounreay, due to be shut down recently for a ten-week overhaul and for refuelling, will meanwhile take over the role of the small experimental reactor, which will be closed in a ceremony next week after some 17 years of service. In the reprocessing field $\mathrm{Mr}$ Benn's intervention last weekend has seen the end of the six-week industrial dispute at the British Nuclear Fuels plant at Windscale.

pairs, separated by a month or so. This is quite an unusual observation for earthquakes, and the prospect of a second large quake cannot be discounted. Prediction techniques based on rock dilatation that are beginning to emerge as important for shallow quakes seem difficult if not impossible to apply at present to events as deep as the Romanian quakes.

The earthquake was felt over a ver, wide area-Moscow, a thousand miles away, was shaken slightly. This had been noted for previous shocks and probably arises from a combination of two factors. First, an earthquake at depth, away from the near surface inhomogeneities, irradiates a larger area than does a shallow shock. And second, there is probably very little absorption of elastic waves crossing an old, stable region such as Western Russia.

Legal proceedings, it is reported, are to be brought against architects whose modern buildings collapsed in the quake. There is a certain amount of sense in this. An earthquake of comparable dimensions occurred in 1940 and was destructive; it seems that in some cases appropriate lessons have not been learnt. Earthquakeproofing of buildings is by no means an impossibly expensive task, and is done routinely in California and Japan, with great success. Maybe one of the good things to emerge from the disaster will be a greater insistence on building to safer standards. 